\title{
ANALYSIS AND PREVENTION OF THE IMPACTS OF METRO CONSTRUCTION ON GROUNDWATER ENVIRONMENT
}

\author{
DAI, C. Q. ${ }^{*}$ HOU, W. Z. - SUI, H. T. \\ Shandong Key Laboratory of Civil Engineering, Disaster Prevention and Mitigation, College of \\ Civil Engineering and Architecture, Shandong University of Science and Technology \\ No. 597, Qianwangang Road, Qingdao 266590, China \\ *Corresponding author \\ e-mail:dcqwin@sdust.edu.cn \\ (Received $5^{\text {th }}$ Feb 2019; accepted $6^{\text {th }}$ Mar 2019)
}

\begin{abstract}
Despite its positive impacts on traffic convenience and resource delivery, metro construction tilts the balance of groundwater resources and destabilizes the groundwater environment. This paper explores the impacts of shield tunnel construction on groundwater environment from the design and construction to an operating metro project, and verifies these impacts through an analysis on the tunnel project in Jinan Metro Line R3. The research shows that the grouting in shield tunneling has a local influence on the groundwater quality and $\mathrm{pH}$, which attenuates with the increase of distance to the tunnel axis; the scope of influence is constrained by the formation lithology. Then, the backpropagation (BP) neural network was adopted to predict the ejection volume of groundwater, and the main influencing factors of water environment were disclosed by analytical hierarchy process (AHP). Finally, the author discussed the key techniques and prevention systems for prevention of the impacts of shield tunnel construction on water environment.
\end{abstract}

Keywords: shield tunnel, backpropagation (BP) neural network, prediction of spring flow, analytical hierarchy process $(A H P)$, key to groundwater control

\section{Introduction and survey of literature}

Metro construction makes traffic convenient and efficient, enhances the overall competitiveness of cities, and improves people's living standards. However, the construction process also has negative impacts on groundwater environment.

During the construction of metro tunnels, dewatering is a necessity for engineering excavation. The rapid discharge of water from the tunneling section undermines the groundwater regulation and the spatial distribution of water resources. With the advancement of the tunnel, an increasing part of the water environment is destroyed, which changes the conditions of water-soil conservation and aggravates the imbalance between surface water and groundwater system. Zheng et al. (2016) and other scholars classified the impact of soft soil, high water level, liquid-rich powder, sand layer and underground engineering construction on the environment and the causes of disasters. Luo et al. (2018) analyzed the characteristics of urban underground engineering, and discussed the environmental hazards of underground engineering construction.

Surface subsidence caused by instability of tunnel excavation will lead to complex environmental problems. Li (2014) analyzed the influence of excavation disturbance zone on surface and surface deformation, and made exploratory research for the selection of excavation design methods and schemes, subsidence prediction and damage evaluation. Surface subsidence changes the water supply, runoff and discharge modes of surrounding water-bearing strata, thus damaging the overlying aquifer and breaking the balance of water environment. Guo (2018) put forward the countermeasures to reduce the adverse impact of tunnel construction on the water environment and improve the 
stability of the water environment system. In the process of tunneling, the water quality of the water environment will be damaged. According to the target layer, criterion layer, element layer and index layer, Fu (2018) constructed the index system and factor set of the influence of underground waterproof construction on water quality in urban tunnel engineering, and analyzed the influence of main pollutants discharged in the process of underground waterproof construction on water quality in urban tunnel engineering. Engineering wastewater discharged into the water environment without treatment will cause pollution of surface water resources, environmental degradation and other ecological problems.

\section{Materials and methods}

\section{Analysis on the impacts of metro construction on groundwater environment}

\section{Overview of metro construction}

The metro tunnel usually passes through several formations with complex geological conditions and diverse geological features. These formations differ greatly in water content, compressibility, void ratio, strength, as well as surface water reserve and topography. Therefore, the tunneling technique needs to be selected in light of the specific geological environment and hydrological conditions.

The shield method is a fully mechanized "deep bore" construction approach. As the shield tunnel boring machine (TBM) advances underground, the surrounding rock is supported by the shell and segments to prevent the tunnel from collapsing, while the soil on the tunnel face is excavated by the cutting device and transported outside the tunnel by the conveyor $(\mathrm{Li}, 2018)$. The advancement is propelled by the pressure of jacks in the rear of the shield TBM. In addition, the precast concrete segments are pieced up to form the tunnel structure.

\section{Analysis on the impacts during the construction}

Metro construction involves the pouring of concrete and the use of other chemicals (Zheng et al., 2016). The injected grouts have a certain impact on the quality and $\mathrm{pH}$ of the water in the surrounding rock. During the construction, the grouts, which contain lots of additives, are injected with the advancement of the shield TBM and added again after the installation of the segments (Guo, 2018). The grouts are prepared from a single type of liquid or two types of liquids. To make the single-liquid grout, the raw material needs to be mixed into a flowing liquid in a stirrer, and then solidified on the working face through flow and plastic condensations. The two-liquid grout generally refers to chemical grouting, i.e. mixing liquid A (cement) and liquid B (water glass) into a colloidal solution, whose viscosity increases with time, and relocating the solution to flow and plastic condensation zones (Cai et al., 2018). The mix ratios of the two types of grouts are listed in the Tables 1 and 2.

The injection of a large amount of grouts can easily pollute groundwater resources. What is worse, epoxy resin and other compounds commonly used in the construction are highly toxic and harmful to the human body (Huang et al., 2018). During the tunneling process, the deep groundwater and shallow groundwater are mixed together. The pollutants in the shallow groundwater will diffuse into the deep groundwater, affecting the direction of the water vein and water quality. 
The impacts of tunneling on water environment are constrained by the formation lithology. The permeability and compactness of the stratum both have an impact on the stability of water environment, which is negatively correlated with the distance to the tunnel axis.

During the construction, the dewatering well directly bears on the water level in the formation, resulting in temporary reduction of water level in local areas and damages to the soil structure. When water is discharged through the well, the groundwater level dropped across the board around the well. The curve on water level variation takes the shape of a funnel. Within the scope of influence, the soil layers will witness a continuous decline in the amount of pore water and the loss of water pressure balance. Meanwhile, the sediment will flow out from broken filter tube and filter layer of the well, reducing the natural compactness, water content and stability of the soil layers.

Table 1. Common mix ratio of single-liquid grout

\begin{tabular}{c|c|c|c|c|c}
\hline Cement (kg) & Fly ash (kg) & Bentonite (kg) & Sand (kg) & Water (kg) & Additives \\
\hline 58 & 410 & 33 & 440 & 335 & $\begin{array}{c}\text { To be determined } \\
\text { through experiment in } \\
\text { light of the field } \\
\text { conditions }\end{array}$ \\
\hline
\end{tabular}

Table 2. Common mix ratio of two-liquid grout

\begin{tabular}{c|c|c}
\hline Water-cement ratio & Liquid A : Liquid B (volume ratio) & Coagulation time (s) \\
\hline $1: 1$ & $1: 1$ & $20 \sim 48$ \\
\hline
\end{tabular}

Analysis on the long-term impacts after the completion

Since the metro construction tilts the original balance of the groundwater environment, the long-term impacts on water environment can be evaluated against the reserve and ejected amount of groundwater. The latter can be predicted using the backpropagation (BP) neural network below (Isah et al., 2017; Li, 2017; Neelapu et al., 2018; Sánchez-Escalona and Góngora-Leyva, 2018; Sun et al., 2017a).

Let $n, m$ and $r$ be the number of neurons on the input layer, output layer and hidden layer in the BP neural network, which will be trained by $\mathrm{K}$ samples. The corresponding $\mathrm{K}$ input-output pairs can be expressed as $\left(X_{k}, Y_{k}\right), k=1,2, \cdots, k$, where $X_{k}=\left(x_{1}, x_{2}, \cdots, x_{n}\right)$ is the input vector of the $\mathrm{k}$-th sample and $Y_{k}=\left(y_{1}, y_{2}, \cdots, y_{n}\right)$ is the output vector of the k-th sample. Meanwhile, the expected value vector, the input layerto-hidden layer weight matrix, and the hidden layer-to-output layer weight matrix are denoted as $D_{k}=\left(d_{1}, d_{2}, \cdots, d_{n}\right), V=\left(V_{1}, V_{2}, \cdots, V_{n}\right), V_{j}=\left(V_{j 1}, V_{j 2}, \cdots, V_{j n}\right)^{T}, j=1,2, \cdots, n$, and $W=\left(W_{1}, W_{2}, \cdots, W_{m}\right) \quad W_{i}=\left(w_{i 1}, w_{i 2}, \cdots, w_{i n}\right)^{T}, j=1,2, \cdots, r$, respectively. The threshold of each hidden layer neuron and that of each output layer neuron can be expressed as $\alpha=\left(\alpha_{1}, \alpha_{2}, \cdots, \alpha_{r}\right)$ and $\beta=\left(\beta_{1}, \beta_{2}, \cdots, \beta_{m}\right)$, respectively. The initial weights and thresholds are configured by random.

Activation function: this function describes the change between the input and output of the neuron. The signals received by the hidden layer and the output layer are excited or suppressed by the calculation of the activation function. Here, the sigmoid function is selected as the activation function Equation 1: 


$$
f(\text { net })=\frac{1}{(1+\exp (- \text { net }))}
$$

where net is the summation unit.

Summation unit Equation 1 represents the weighted summation of the input signals of the hidden layer (He, 2018). Since the weighted input of the hidden layer unit $\mathrm{j}$ is net $b_{j}=x_{k} \cdot v_{j}+a_{j}$, the actual output of the hidden layer unit Equation 1 can be expressed as Equation 2:

$$
b_{f}=\left(\text { net } b_{j}\right), j=1,2 \cdots, n
$$

Thus, the output matrix can be obtained as $B_{k}=\left(b_{1}, b_{2}, \cdots b_{r}\right)$.

Summation unit Equation 2 represents the weighted summation of the input signals of the output layer. Since the weighted input of the output layer unit i is nety $y_{j}=b_{k}{ }^{*} w_{i}+\beta_{i}$, the actual output of the output layer unit Equation 2 can be expressed as Equation 3:

$$
y_{i}=f\left(\text { nety }_{i}\right), i=1,2 \cdots r_{j} j=1,2, \cdots, n
$$

Error calculation and backpropagation: Taking the root mean square errors of the output value and the expected value as the loss functions, the error index function of learning a single sample and the global error index function of learning the entire training set can be respectively expressed as Equations 4 and 5:

$$
\begin{gathered}
E_{k}=\frac{1}{2} \sum_{i=1}^{m}\left(y_{i}-d_{i}\right)^{2}=\frac{1}{2} \sum_{i=1}^{m}\left\{f\left\{\left[\sum_{j=1}^{r} f\left(x_{k} \cdot v_{j}+\alpha_{j}\right) \cdot w_{i j}\right]+\beta_{i}\right\}-d_{i}\right\}^{2} \\
E=\sum_{i=1}^{k} E_{k}
\end{gathered}
$$

The learning and training of the BP neural network generally rely on the negative gradient descent method to adjust weights and thresholds. Based on Equations 1-3, the adjusted values of the weights and thresholds can be obtained through derivation by the complex function chain law, as shown in Equations 6-9:

$$
\begin{aligned}
& \Delta v_{j}=-\mu \frac{\partial E_{k}}{\partial v_{j}}, j=1,2, \cdots, n \\
& \Delta \alpha_{j}=-\mu \frac{\partial E_{k}}{\partial \alpha_{j}}, j=1,2, \cdots, r \\
& \Delta \beta_{j}=-\mu \frac{\partial E_{k}}{\partial \beta_{j}}, j=1,2, \cdots, m \\
& \Delta w_{j}=-\mu \frac{\partial E_{k}}{\partial w_{j}}, j=1,2, \cdots, r
\end{aligned}
$$

where $\mu \in(0,1)$ is a constant representing the learning efficiency.

The adjusted weights and thresholds are adopted for the calculation of the next training sample. The learning should be terminated when the global error reaches the pre-set value after learning all training samples. Otherwise, the weights and thresholds should be initialized again for a new round of training until the said termination condition is satisfied. 


\section{Evaluation of the negative impacts of metro construction on water environment}

Analysis on the negative impacts on water environment

The negative impacts on water environment can be determined through the judgement of water environment damages caused by human activities and their impacts (Dai and Lv, 2018). In this paper, the analytical hierarchy process (AHP) is employed to scientifically assess water environment problems induced by tunnel construction (Dai and Zhao, 2018). The assessment was carried out in the following steps.

(1) Setting up the judgement matrix: Denote the target as A, the factors as $u_{i}$ and $u_{j}(i$, $j=1,2, \cdots, \mathrm{n}$ ) and the importance of $u_{i}$ to $u_{j}$ as $u_{i j}$ (Sun et al., 2017b). On this basis, construct the A-U judgment matrix $\mathrm{P}$ below:

$$
p=\left[\begin{array}{cccc}
u_{11} & u_{12} & \ldots & u_{1 n} \\
u_{21} & u_{22} & \ldots & u_{2 n} \\
\ldots & \ldots & \ldots & \ldots \\
u_{n 1} & u_{n 2} & \ldots & u_{n n}
\end{array}\right]
$$

(2) Calculating the importance rank: Find the eigenvector $w$ corresponding to the largest characteristic root $\lambda_{\max }$, according to the judgement matrix, as shown in Equation 10:

$$
P_{w}=\lambda_{\max } \cdot w
$$

Normalize the obtained eigenvector $\mathrm{w}$, that is, sort the importance of all evaluation factors, yielding the weight distribution.

(3) Consistency test: Check if the weights are reasonable through consistency test on the judgement matrix, as shown in Equation 11:

$$
C R=\frac{C I}{R I}
$$

where $\mathrm{CR}$ is the random consistency ratio of the judgment matrix; $\mathrm{CI}$ is the general consistency index of the judgment matrix, as shown in Equation 12:

$$
C I=\frac{\lambda_{\max }}{n-1}
$$

The RI is the mean random consistency index of the judgment matrix $\mathrm{P}$. If the $\mathrm{CR}$ of the judgment matrix $\mathrm{P}$ is smaller than 0.1 or $\lambda_{\max }=\mathrm{n}$ and $\mathrm{CI}=0$, then the judgment matrix has satisfactory consistency; otherwise, the elements in the matrix should be adjusted to ensure the consistency. The negative effect of water environment is evaluated by ahp to realize the health analysis of water environment (Yang, 2018).

\section{Results}

\section{Analysis of the influence of Jinan subway construction on groundwater environment}

Jinan, the capital of Shandong Province, China, is widely known as the City of Springs. It is said that "every household in the city has a willow-shaded spring at the 
doorstep." There are many water bodies in the city, including the Yellow River, the Yufu River, the Beisha River, the Xiaoqing River and the Daming Lake. Unfortunately, the construction of Jinan Metro Line R3 has disturbed the topography, stratum altitude, stratum lithology and geological structure, hindered the ejection of underground springs and damaged the balance of groundwater environment. Located in the east of the city, Line R3 is a $49.4 \mathrm{~km}$-long north-south express line linking up transport hubs like the new East Railway Station and Yaoqiang Airport. Many water bodies are scattered along the route of the line, such as the Xiaoqing River, the Daxin River, the Zhangma River, the Longji River, the Hancang River and the Mengjiazhuang Reservoir.

The construction area of Line R3 spans northward to the west of the springs in the Baiquan Spring Area, and belongs to the discharge zone of the area. The relative location between the project site and the Baiquan Spring Area is shown in Figures 1 and 2.

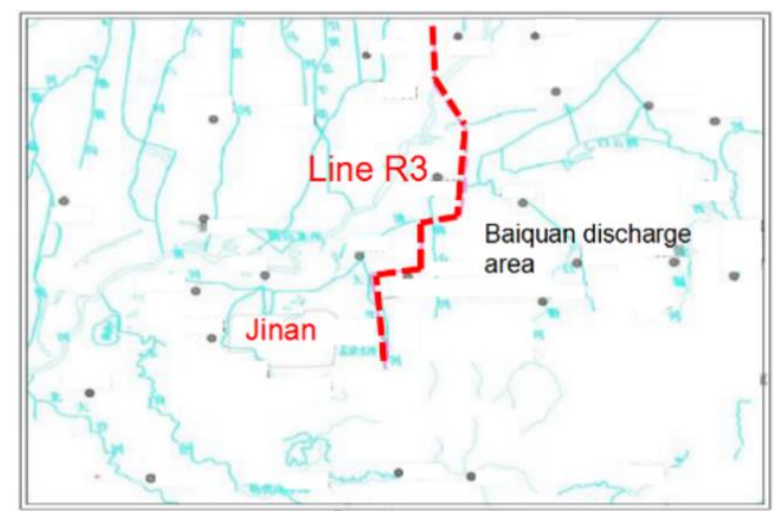

Figure 1. Project site of Jinan Metro Line R3

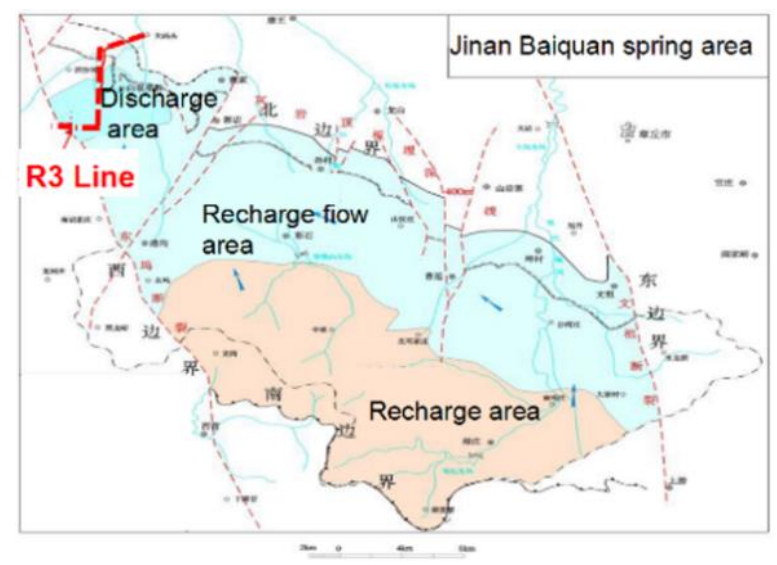

Figure 2. Baiquan Spring Area

The Mengjiazhuang Long'ao section, an important passenger section of Line R3, is located in Lixia District of Jinan. Starting from the Mengjiazhuang Station, the metro line goes north along the Longding Avenue to the headquarters of the Armed Police Fire Corps, and then turns slightly towards the west, crossing the Daxin River and a mountain, and finally reaches the Long'ao Station on the Olympic West Road to the west of the Municipal Procuratorate. In this section, the crossings are mostly 
underground, along the road direction. The main environmental risk sources include the Daxin River, the DN1000 raw water pipe at the river bottom, and several roads undercrossed by the metro line, as well as the developed caverns near the side-crossing of the Daxin River Bridge. In the target section, the 1,816.811 m-long right line is designed between SK1 + 909.933 (right) and SK3 + 726.744 (right), while the left line of the same length is designed between XK1 + 909.933 (left) and XK3 + 726.744 (left). Constructed by shield tunneling, the tunnel in the section has a standard single-hole single-line circular profile. The left and right lines are both composed of straight segments, three circular curve segments with radius $\mathrm{R}=1,000 \mathrm{~m}$, and gentle curve segments. The line spacing is $13 \sim 14 \mathrm{~m}$, and the covering soil is $2.3 \sim 80 \mathrm{~m}$ thick.

The construction area is dominated by south-north flowing pore water, which is replenished by the upstream runoff, karst water from the roof, and the atmospheric rainfall. The water is eventually discharged into the Xiaoqing River.

Since Line R3 lies in the discharge zone of Baiquan Spring Area, the first tunnel segment (north) in the Mengjiazhuang Long'ao section passes through a 1,232.266 mlong layer of moderately weathered limestone and marlstone, while the second segment (south) through a $584 \mathrm{~m}$-long gravel layer and the enrichment zone of karst groundwater in Baiquan Spring Area. Considering the dense water outlets, a huge amount of twoliquid grout was injected in actual construction. The liquid B is sodium water glass $\mathrm{Na}_{2} \mathrm{O} \cdot \mathrm{nSiO}_{2}$, a popular chemical in civil engineering. The relevant chemical reaction can be described by the following formula:

$$
x \mathrm{Ca}(\mathrm{OH})_{2}+\mathrm{Na}_{2} \mathrm{O} \cdot \mathrm{nSi} \mathrm{O}_{2}+\mathrm{mH}_{2} \mathrm{O}=\mathrm{xCaO} \cdot \mathrm{SiO}_{2} \cdot \mathrm{yH}_{2} \mathrm{O}+2 \mathrm{NaOH}
$$

The product $\mathrm{NaOH}$ is alkaline. The two-liquid grout affects the $\mathrm{pH}$ of the water system around the grouting project and changes the $\mathrm{pH}$ of the local groundwater. The analysis results on local water sample are presented in Figure 3.

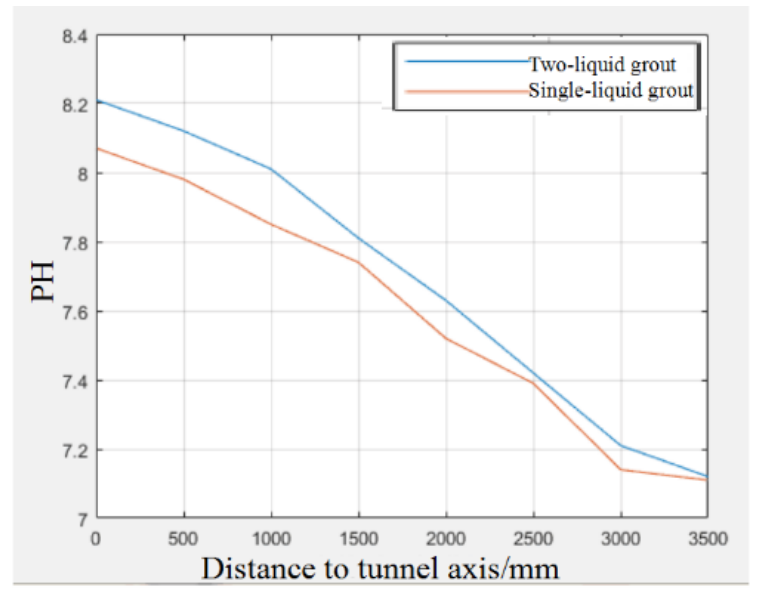

Figure 3. The pH curve of local water sample

As shown in Figure 3, the two grouts significantly pushed up the $\mathrm{pH}$ of the water around the tunnel, and the two-liquid grout had a greater impact on the $\mathrm{pH}$ than any single-liquid grout. This is because the two-liquid grout, as the main filling material, exerted an impact on the $\mathrm{pH}$ of the water in the secondary grouting, and the grouting process damaged the internal environment of the rock and soil, affecting the flow path 
of the water system. The author carried out an experiment on how much the tunnel blocks the water system, which shows that the grouting enhanced the water blocking effect by $20 \%$ 30\% from that of cylinder volume of the tunnel.

Through investigation, it is learned that the scope of influence on water environment is maximal at the crossing through the gravelly soil layer, followed in descending order by the crossing through moderately weathered limestone and diorite, and the crossing through the silty clay layer.

As shown in Table 3, the impacts of the tunnel project on water environment belong to the $0 \sim 5,000 \mathrm{~m}$ from either side of the tunnel axis in the gravelly soil layer. Specifically, the severely affected area generally concentrates in the $0 \sim 1,500 \mathrm{~m}$ from either side of the tunnel axis. This area is characterized by the water seepage from Mengjiazhuang Reservoir, the depletion of surface water, wells and springs in the surroundings, the settlement, subsidence and cracking of the ground, and the complete change of the land use. The heavily affected area concentrates in the 1,500 3,000 m from either side of the tunnel axis. This area is characterized by the severe leakage of surface water, though not complete dry, obvious reduction of groundwater level, small local ground subsidence and change of local land use. The general affected area concentrates in the 3,000 5,000 $\mathrm{m}$ from either side of the tunnel axis. This area is characterized by the slight leakage of surface water and unobvious change of groundwater level.

Table 3. Influence of formation lithology on water environment during metro construction

\begin{tabular}{|c|c|c|c|c|}
\hline & $\begin{array}{l}\text { Gravelly soil } \\
\text { layer }\end{array}$ & $\begin{array}{l}\text { Moderately weathered } \\
\text { limestone layer } \\
\text { (fragmented, with } \\
\text { moderately developed } \\
\text { caverns) }\end{array}$ & $\begin{array}{l}\text { Moderately } \\
\text { weathered } \\
\text { limestone and } \\
\text { diorite layer }\end{array}$ & $\begin{array}{l}\text { Silty clay } \\
\text { layer }\end{array}$ \\
\hline $\begin{array}{c}\text { Permeability } \\
\text { coefficient }\left(10^{-6} \mathrm{~cm} / \mathrm{s}\right)\end{array}$ & 8000 & 9000 & 6000 & 50 \\
\hline $\begin{array}{c}\text { Scope of influence } \\
\text { (relative to the tunnel } \\
\text { axis) }\end{array}$ & $0 \sim 5000 \mathrm{~m}$ & $0 \sim 3000 \mathrm{~m}$ & $0 \sim 2000 \mathrm{~m}$ & $0 \sim 1000 \mathrm{~m}$ \\
\hline $\begin{array}{c}\text { Affected areas } \\
\text { (relative to the tunnel } \\
\text { axis) }\end{array}$ & $0 \sim 1500 \mathrm{~m}$ & $0 \sim 1000 \mathrm{~m}$ & $0 \sim 800 \mathrm{~m}$ & $0 \sim 500 \mathrm{~m}$ \\
\hline $\begin{array}{l}\text { Phenomena in the } \\
\text { severely affected area } \\
\text { (relative to the tunnel } \\
\text { axis) }\end{array}$ & $\begin{array}{l}\text { Water seepage } \\
\text { from } \\
\text { Mengjiazhuang } \\
\text { Reservoir; } \\
\text { depletion of } \\
\text { surface water, } \\
\text { wells and springs } \\
\text { in the } \\
\text { surroundings }\end{array}$ & $\begin{array}{l}\text { Severe leakage of surface } \\
\text { water, though not } \\
\text { completely dry; obvious } \\
\text { reduction of groundwater } \\
\text { level }\end{array}$ & $\begin{array}{c}\text { Slight leakage of } \\
\text { surface water; } \\
\text { unobvious change } \\
\text { of groundwater } \\
\text { level }\end{array}$ & $\begin{array}{l}\text { Slight leakage } \\
\text { of surface } \\
\text { water }\end{array}$ \\
\hline
\end{tabular}

In the moderately weathered limestone layer (fragmented, with moderately developed caverns), the tunnel project has a moderate scope of influence on water environment, which covers the $0 \sim 3,000 \mathrm{~m}$ from either side of the tunnel axis. Specifically, the severely affected area generally concentrates in the $0 \sim 1,000 \mathrm{~m}$ from 
either side of the tunnel axis. This area is characterized by the severe leakage of surface water, though not complete dry, obvious reduction of groundwater level, small local ground subsidence and change of local land use. The general affected area concentrates in the 1,500 2,000 $\mathrm{m}$ from either side of the tunnel axis. This area is characterized by the slight leakage of surface water and unobvious change of groundwater level.

In the moderately weathered limestone and diorite layer, the tunnel project has a small scope of influence on water environment, which covers the $0 \sim 2,000 \mathrm{~m}$ from either side of the tunnel axis. Specifically, the severely affected area falls in 0 800, which is characterized by the slight leakage of surface water and unobvious change of groundwater level.

In the silty clay layer, the impacts of the tunnel project on water environment belong to the $0 \sim 1,000 \mathrm{~m}$ from either side of the tunnel axis. The severely affected area falls in 0 500 $\mathrm{m}$, which is characterized by the slight leakage of surface water.

Near the target metro section, the large surface water systems include the Daxin River, which has a large north-south height difference, and the Mengjiazhuang Reservoir, which is rich in water resources. The groundwater beneath the riverbed is formed by the infiltration of rainwater along the gravel and bedrock fissures. The groundwater level is not uniform and varies greatly from season to season. The field survey on the reservoir confirms that there are 33 spring water outlets in the reservoir area (Figures 4 and 5), including 9 active springs and 24 inactive ones.

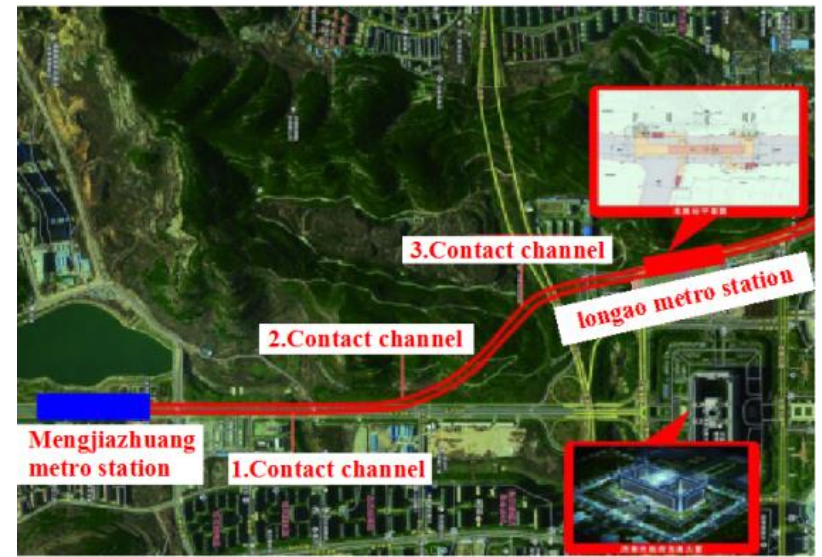

Figure 4. Geographical map of Mengjiazhuang Reservoir

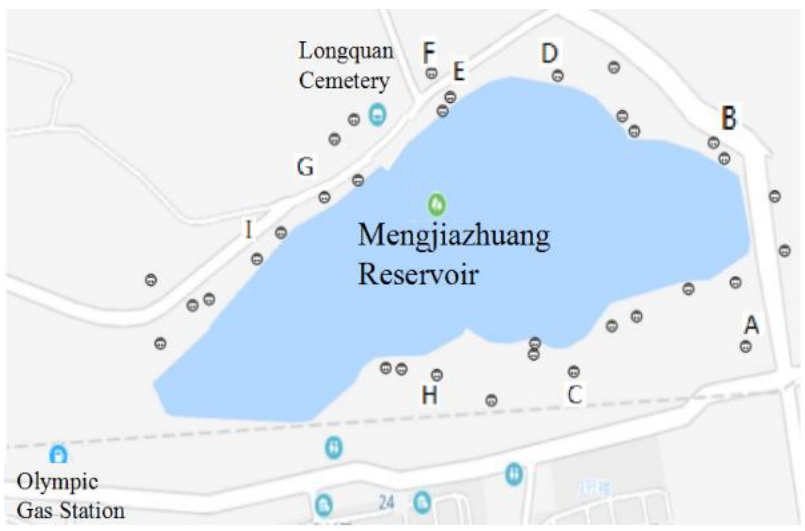

Figure 5. Distribution of spring water outlets near Mengjiazhuang Reservoir 
Here, the water ejection volume of each inactive spring is estimated by the BP neural network (Fu, 2018), while the water amount of the 9 active springs are analyzed by water volume monitoring. As shown in Table 4, the water ejection volume of spring outlet A was reduced by $26 \%$ and that of spring outlet I was reduced by $3 \%$, due to the tunnel blockage and geological disturbances.

Table 4. Daily ejection volume of active springs

\begin{tabular}{c|c|c|c|c|c|c|c|c|c}
\hline Spring No. & A & B & C & D & E & F & G & H & I \\
\hline $\begin{array}{c}\text { Pre-excavation ejection volume } \\
\left(\mathrm{m}^{3} / \mathrm{d}\right)\end{array}$ & 2.051 & 0.304 & 4.547 & 0.841 & 0.592 & 2.820 & 1.426 & 0.975 & 0.106 \\
$\begin{array}{c}\text { Post-completion ejection } \\
\text { volume }\left(\mathrm{m}^{3} / \mathrm{d}\right)\end{array}$ & 1.518 & 0.274 & 4.092 & 0.774 & 0.539 & 2.679 & 1.369 & 0.678 & 0.103 \\
Reduction $(\%)$ & 26 & 15 & 10 & 8 & 9 & 5 & 4 & 11 & 3 \\
\hline
\end{tabular}

The measuring points were arranged at an interval of $200 \mathrm{~m}$ to monitor the groundwater level near Mengjiazhuang Reservoir. Then, the variation in the ejection volume of each active spring was predicted based on the monitoring data. The deviation between the predicted value and the original value was plotted as a curve in Figure 6. It can be seen that the predicted value agrees well with the original value, indicating that the prediction result is close to reality.
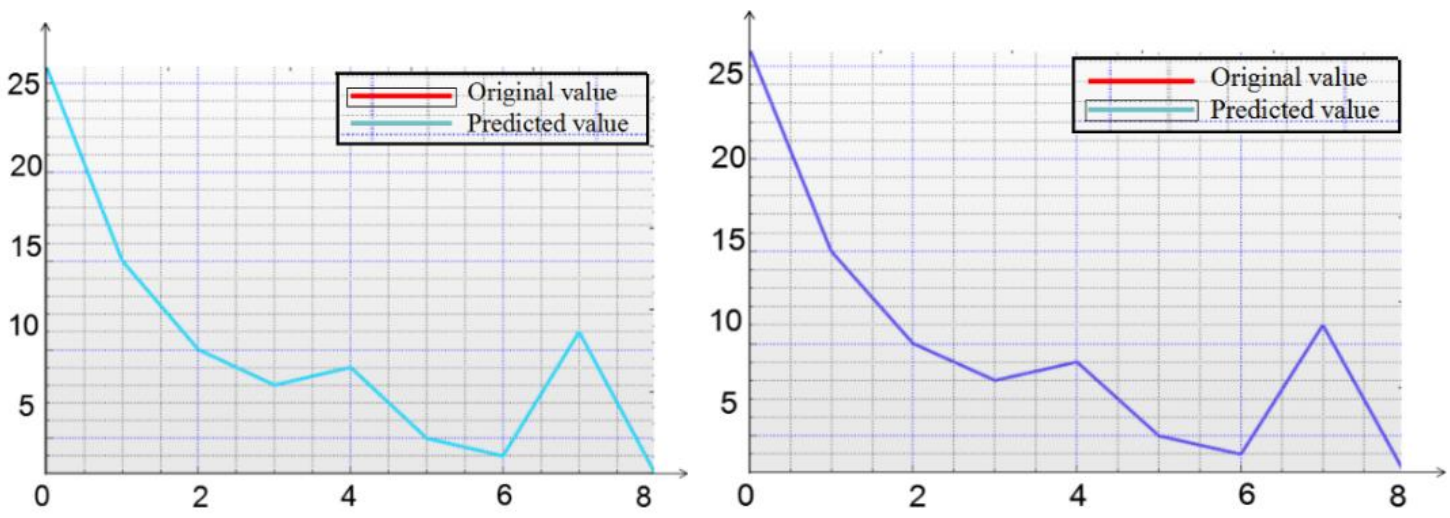

Figure 6. Deviation between the predicted value and the original value

The analysis on the prediction result shows that the metro tunnel construction caused an average reduction of $16 \%$ in the ejection volume of the active springs near Mengjiazhuang Reservoir. Besides, the ejection volume is correlated with the location of water outlets: the closer to the tunnel, the more the reduction in the ejection volume; the inverse is also true.

\section{Analysis of the negative effects of subway construction on water environment}

The target tunnel was divided into four parts (Table 5) according to the difference in geological conditions and covering soil environment of Line R3. Through the AHP, the judgment indices were allocated to three categories, namely, engineering geological conditions (Fang et al., 2018), hydrogeological conditions, and tunnel engineering 
conditions, and sub-divided into 13 special groups. Finally, 80 experts were invited to evaluate these indices. In this way, the author acquired the weights of the negative impacts of metro construction on water environment in the target metro section.

Table 5. Division of groups and categories

\begin{tabular}{c|c|c|c|c|c|c}
\hline No. & Mileage & Length/m & $\begin{array}{c}\text { Crossed } \\
\text { stratum }\end{array}$ & Overlying stratum & $\begin{array}{c}\text { Roof } \\
\text { depth/m }\end{array}$ & $\begin{array}{c}\text { Construction } \\
\text { environment }\end{array}$ \\
\hline A & SK3+726.7 SK3+400 & 326.7 & $\begin{array}{c}\text { Moderately } \\
\text { weathered } \\
\text { limestone }\end{array}$ & $\begin{array}{c}\text { Plain fill, silty clay, } \\
\text { gravelly soil }\end{array}$ & $15.23-28.33$ & $\begin{array}{c}\text { Crossing rainwater } \\
\text { box culvert and tourist } \\
\text { road }\end{array}$ \\
\hline B & SK3+400 SK2+460 & 940 & $\begin{array}{c}\text { Moderately } \\
\text { weathered } \\
\text { limestone }\end{array}$ & $\begin{array}{c}\text { Plain fill, } \\
\text { moderately } \\
\text { weathered diorite, } \\
\text { gravelly soil }\end{array}$ & $2.31-80$ & $\begin{array}{c}\text { Crossing mountain, } \\
\text { karst caves, the Daxin } \\
\text { River and DN1000 } \\
\text { raw water pipe }\end{array}$ \\
\hline C & SK2+460 SK2+280 & 180 & $\begin{array}{c}\text { Moderately } \\
\text { weathered } \\
\text { limestone, } \\
\text { gravelly soil }\end{array}$ & $\begin{array}{c}\text { Plain fill, silty clay } \\
\text { Crossing DN600 }\end{array}$ & $11.15-12.55$ & $\begin{array}{c}\text { rainwater pipe; the } \\
\text { stratum is soft on the } \\
\text { top and hard on the } \\
\text { bottom }\end{array}$ \\
\hline D & SK2+280 SK1+909.9 & 370.1 & $\begin{array}{c}\text { Gravelly soil, } \\
\text { silty clay }\end{array}$ & Plain fill, silty clay & $10.47-13.1$ & $\begin{array}{c}\text { Crossing the planed } \\
\text { road and DN400 heat } \\
\text { pipe }\end{array}$ \\
\hline
\end{tabular}

The weights (Fig. 7) were determined through selection of the evaluation method, construction of the evaluation model, the identification of the evaluation indices and the weight analysis.

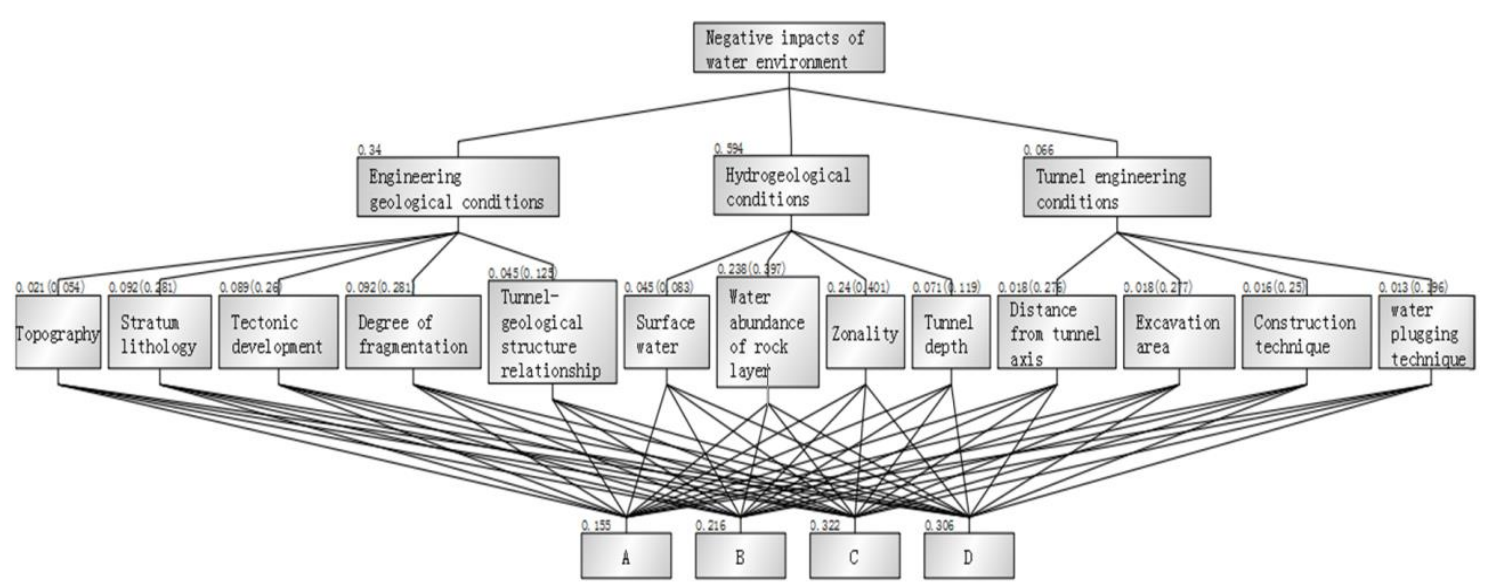

Figure 7. AHP analysis on tunnel water environment

The AHP weight analysis reveals that the negative impacts on water environment mainly come from the hydrogeological conditions (Tang et al., 2019). In the target tunnel, the SK2 + 460 SK2 + 280 segment had the greatest negative impacts on water environment, followed by the SK2 + 280 SK1 + 909.9 segment and the SK3 + 726.7 SK3 + 400 segment. 


\section{Discussion}

\section{Prevention of the impacts of metro construction on groundwater environment}

\section{Key prevention technologies}

To reduce the impacts of metro construction on groundwater environment, it is necessary to step up prior control, rationalize route selection and optimize the design. The design plan should be pertinent and the planned route should be optimized according to the survey report. If a section of poor geological conditions is unavoidable, the best construction plan must be prepared in light of the geological conditions and construction technologies.

As mentioned before, the shield tunnel has a certain blocking effect on the flow of groundwater. It is impossible to identify the direction of all spring waters through geological survey, for the water flow of most small springs, generated the infiltration of surface water, may be affected by the stratum and groundwater level. To minimize the impacts of formation damage on spring water, fixed-point monitoring should be carried out on the water pressure of the water and soil layer near the tunnel, and recharge technique should be adopted to replenish the spring water.

As a permanent project, the tunnel will have an impact on the groundwater environment. In the short term, the local osmotic pressure of the water will be greatly affected, which will change the flow direction of the groundwater. The sealing effect of the multi-layer grouting on the water will induce changes to the groundwater system. To reduce the damage of grouts on water environment, it is advised to adopt high-quality shield segments, enhance the water resistance of the segments, standardize the field construction process, and cut down the amount of secondary grouting.

Considering the health impacts of groundwater quality and $\mathrm{pH}$, the tunneling damages on water environment must be minimized. To lower the material pollution to water environment, the possible measures include replacing toxic compounds with green materials and traditional construction techniques with advanced techniques.

\section{Main prevention techniques}

The in-process control and post-action control should also be enhanced during metro construction. The water level should be reduced to about $50 \mathrm{~mm}$ below the excavation face when the last 3 5 ring segments are installed, so that no water or sand will flow out at the tunnel breakthrough. To meet this goal, it is recommended to implement in-situ dewatering at the recharge well (Guo et al., 2018). The process flow of this technique is shown in Figure 8. It can be seen that the pumping device is used to lower the water level of the excavated soil layer to below the excavation face.

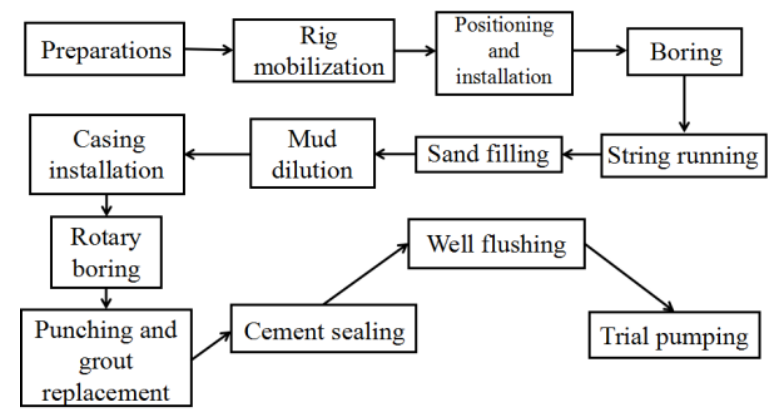

Figure 8. In-situ dewatering at the recharge well 
As the water is injected back into the well, the groundwater level around the well will gradually rise, and the post-injection water level is called the recharge level. The water injected into the well can seep into the aquifer, owing to the water head difference between the recharge level and the groundwater level. When the recharge well is under construction in the foundation pit, the static water level and the dewatering-induced water level variation should be observed, so as to determine the remaining construction of the well. The recharge should commence if the groundwater level changes by over $300 \mathrm{~mm}$ per day, and stop if the recharge amount reaches $80 \%$ or the ground heaves. The recharge water mainly comes from the groundwater in the pumping well within the foundation pit. No additional pressure is needed in the early phase of the recharge. However, a proper amount of external pressure should be applied if the groundwater level cannot meet the target or the recharge amount is difficult to increase. Note that the recharge pressure should not be too large, but controlled within $0.5 \mathrm{MPa}$. During the recharge, the water level should be monitored every $12 \mathrm{~h}$ in the observation wells inside and outside the foundation pit. Meanwhile, the pumping well in the foundation pit should continue to operate.

\section{Key techniques for water environment management in Jinan}

The areas with developed water systems should be avoided in the design phase of the metro tunnels in Jinan. To protect springs, the metro lines should be circumvent springs and avoid water veins. Special efforts should be paid to set up a wide network of water level monitoring systems, covering 2 3 times the area of normal water level detection systems. In addition, the shield segments must contain sealing strips and receive testing before use, aiming to minimize the risk of water leakage due to broken sealing strips.

According to the above design requirements, the in-situ recharge should be performed in time after the dewatering of the tunnel and stations in the target section. The in-situ recharge of groundwater can be controlled in an automatic and precise manner, through the coordination between pressurized recharge well, large variable diameter pressurized recharge well, surrounding water environment detection system, integrated pumping and recharge device and smart control system. The test data show that the overall recharge rate surpassed $80 \%$, indicating that the proposed techniques can effectively protect the total amount of water resources, stabilize the groundwater pressure and maintain the balance of the groundwater environment.

\section{Prevention system}

The metro construction brings a wide range of far-reaching and long-lasting damages on water environment (Zhang et al., 2017). To protect the water resources of Jinan, the author set up a prevention system against the negative impacts on water environment, covering the entire process from design, construction, operation to maintenance. As shown in Figure 9, the proposed system relies on big data collection and analysis platforms (e.g. digitalization, the Internet of Things, cloud computing and collaborative management), integrates underground engineering construction techniques, and involves such systems as organizational system, capital system and institutional system. The system supports real-time warning or adjustment according to geological, hydrological, and engineering inspection data, realizes the intelligent decision-making on the prevention of negative impacts on water environment, and achieves the dynamic optimization of water environment treatment techniques and processes. 


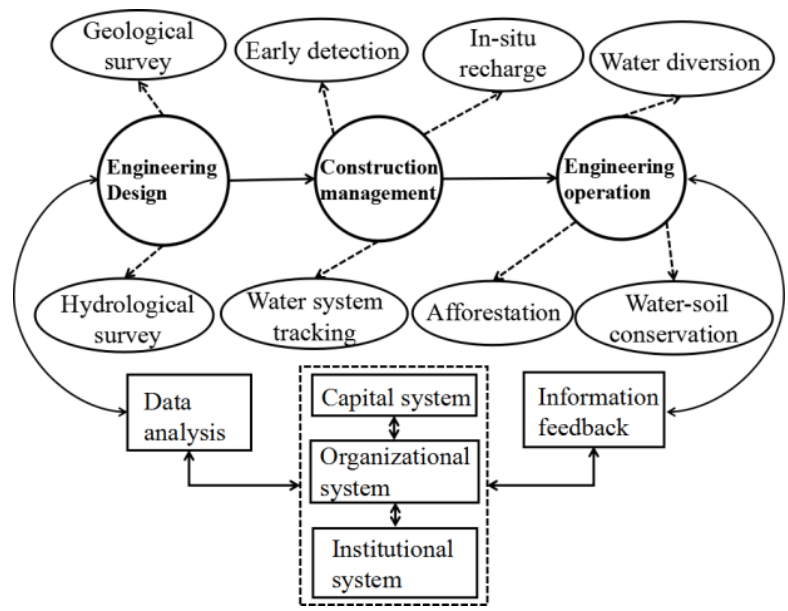

Figure 9. The whole process prevention system against negative impacts on water environment

During the engineering design, the survey data on water level are is analyzed by cloud computing and collaborative management system, and the results are directly applied to the construction management. The construction plan is guided by the realtime data on the field water environment, which are collected through water system tracking and early detection during the design and construction management, laying a solid basis for emergency instructions and groundwater protection.

In this paper, the in-situ recharge in Jinan uses an intelligent control system for integrated pumping and recharge. Coupled with the prevention system, the intelligent control system can promote the protection of water environment. During the project operation, water-soil conservation and afforestation work will be carried out to protect the soil and water resources in a targeted manner. The whole system forms a closedloop control through the feedback mechanism, which can effectively reduce the negative effects of underground engineering on water environment and protect water environment.

\section{Conclusions}

During metro construction, it is imperative to maintain the original groundwater quality and flow, reduce the impacts on the surrounding water environment, and coordinate the relationship between metro construction and water environment.

(1) In this paper, the impacts of shield tunnel construction on groundwater environment are analyzed in the entire process from construction to operation. The research shows that the shield grouting can affect the quality and $\mathrm{pH}$ of groundwater in local areas, and the effect attenuates with the increase of the distance to the tunnel axis. These results were verified through the analysis on the construction of a section in Jinan Metro Line R3.

(2) The impacts of metro tunnel construction on water environment are constrained by stratum lithology, and abide by a certain law. This law was identified as "small in the distance and big on the contrary", based on the data collected from the section between Mengjiazhuang Station and Long'ao Station in Jinan Metro Line R3.

(3) The BP neural network was adopted to predict the reduction of groundwater flow induced by metro construction. Meanwhile, the ejection volumes of 24 active springs 
near Mengjiazhang Reservoir were predicted. Through these predictions, it is concluded that the ejection volume of the local springs will be reduced by $16 \%$ on average.

(4) The main factors were acquired concerning the impacts of metro construction on water environment through the AHP. The analysis shows that the negative impacts on water environment in the target section mainly come from hydrogeological conditions, and peak in the SK3 + 726.7 SK3 + 400 segment.

(5) The author put forward the key prevention techniques for the negative impacts on water environment, and constructed a five-in-one prevention model for negative impacts on water environment, which consists of a construction system, a data analysis system, an organizational system, a capital system and an institutional system.

(6) During the construction of metro tunnels, Multi-angle analysis technology and judgment indicators can better protect the groundwater environment. In-depth exploration of the influence factors of underground engineering on the water environment and comprehensive analysis of the negative effect data of groundwater environment will be the focus of future research on the impact of underground engineering on the water environment and prevention.

Acknowledgements. This work is supported by Natural Foundation of Shandong Province, China [Grant No. ZR2017MEE069]. Thanks for the support of Natural Foundation of Shandong Province.

\section{REFERENCES}

[1] Cai, D. G., Ye, F., Cao, K., Yang, B. P., Xiong, W. (2018): Laboratory test of grouting slurry diffusion in sand shield tunneling. - Chinese Journal of Highways 31(10): 274-283.

[2] Dai, C. Q., Lv, Y. L. (2018): A novel image enhancement technique for tunnel leakage image detection. - Tunnel Leakage Image Detection Technique 35: 209-222.

[3] Dai, C. Q., Zhao, Z. H. (2018): Survey on rheological behaviour of weakly cemented soft rock considering water deterioration. - Journal of Advanced Oxidation Technologies 21(2): 334.

[4] Fang, Z. F., Wang, J. D., Bian, F., Zhang, Y. R., Zhang, J. Z. (2018): Study on the relationship between water permeability and microstructure of concrete. - Concrete 8: 1012.

[5] Fu, Y. (2018): Analysis and research on the influence of underground waterproof construction on water quality of urban tunnel engineering. - Environmental Science and Management 12: 109-113.

[6] Guo, Z. X. (2018): Influence of tunnel construction on water environment and countermeasures. - Building Materials and Decoration 9: 251-252.

[7] Guo, C. X., Guan, X. M., Shi, L. L. (2018): The influence of earth pressure balanced shield tunnel underpassing coastal water body on stratum deformation. - Journal of Coastal 83: 237-146.

[8] He, Y. J. (2018): Analysis of synchronous grouting technology for shield tunneling construction in water-rich strata. - China High and New Technology 18: 44-46.

[9] Huang, Z. H., Zhu, Z. Q., Zhou, Z. H. (2018): Harmful gas reduction through synthesis of epoxy resin aqueous dispersion. - Revue des Composites et des Matériaux Avancés 28(4): 529-538.

[10] Isah, O. R., Usman, A. D., Tekanyi, A. M. S. (2017): A hybrid model of PSO algorithm and artificial neural network for automatic follicle classification. - International Journal Bioautomation 21(1): 43-58. 
[11] Laureano (2019): Synthesis of heat exchanger networks with economic and environmental assessment using fuzzy-Analytic Hierarchy Process. - Chemical Engineering Science 195: 185-200.

[12] Li, G. (2018): Application of foundation pit dewatering recharge technology in Jinan subway. - Construction Technology 47(1): 79-83.

[13] Li, P. (2014): Numerical Simulation of Geological Environment Deformation and Stress Effect Caused by Excavation under Fengsheng Site. - Chongqing Jiaotong University, Chongqing Shi.

[14] Li, Z. J. (2017): Application of neural network technology in machining error recovery. Academic Journal of Manufacturing Engineering 15(3): 6-11.

[15] Liang, J. P., Liu, Y. L., Zhao, G. J., Liu, Y., Ma, P. (2017): Establishment of an evaluation index system for the influence of tunnel construction on water environment in karst areas. - Environmental Engineering 35(04): 129-133.

[16] Luo, J. H., Liu, X. L., Huang, H. F., Mi, D. C., Chen, D. Q. (2018): Mechanism analysis and application of cement-soil mixing pile in soft roadbed treatment. - Revue des composites et des Matériaux Avancés 28(2): 161-172.

[17] Neelapu, R., Devi, G. L., Rao, K. S. (2018): Deep learning based conventional neural network architecture for medical image classification. - Traitement du Signal 35(2): 169182.

[18] Sánchez-Escalona, A. A., Góngora-Leyva, E. (2018): Artificial neural network modeling of hydrogen sulphide gas coolers ensuring extrapolation capability. - Mathematical Modelling of Engineering Problems 5(4): pp. 348-356.

[19] Sun, B., Xu, J. X., Peng, Y. M., Lin, G. Q. (2017a): coordination evaluation of Jinan urban construction and spring water ecological environment protection. - People's Yellow River 39(6): 77-81.

[20] Sun, B. L., Sun, G., Zhang, C. N., Shi, J. W., Zhong, Y. Q. (2017b): Atmospheric pollutants concentration prediction based on BP neural network. - Journal of Environmental Science 05: 34-36.

[21] Tang, L. D., Yuan, S. Q., Tang, Y. (2019): Optimization of impulse water turbine based on GA-BP neural network arithmetic. - Journal of Mechanical Science and Technology 33(1): 241-253.

[22] Yang, C. G. (2018): Application of analytic hierarchy process (ahp) to the evaluation of ecological environment quality in Hefei. - Industry and Technology BBS 17(24): 81-82.

[23] Zhang, G. Z., Cui, S. D., Zhang, H. W., Xu, M. F. (2017): Impact of tunnel engineering on ecological environment and environmental effects. - Geological Hazards and Environmental Protection 28(4): 53-57.

[24] Zheng, G. Z., Liu, X. R., Yang, G. H. (2016): Foundation pit engineering and underground engineering safety and environmental impact control. - Journal of Civil Engineering 49(6): 1-24. 